\title{
Sådan uploader du html-filer, der indeholder billeder, i OJS 3.2
}

Husk: Når du linker til et billede i din html-fil, skal du blot anføre navnet på din billedfil, inkl. filformat: <img src="filename.jpg">. Herefter uploader du html-fil og billeder på følgende måde.

Upload først html-filen som artikeltekst

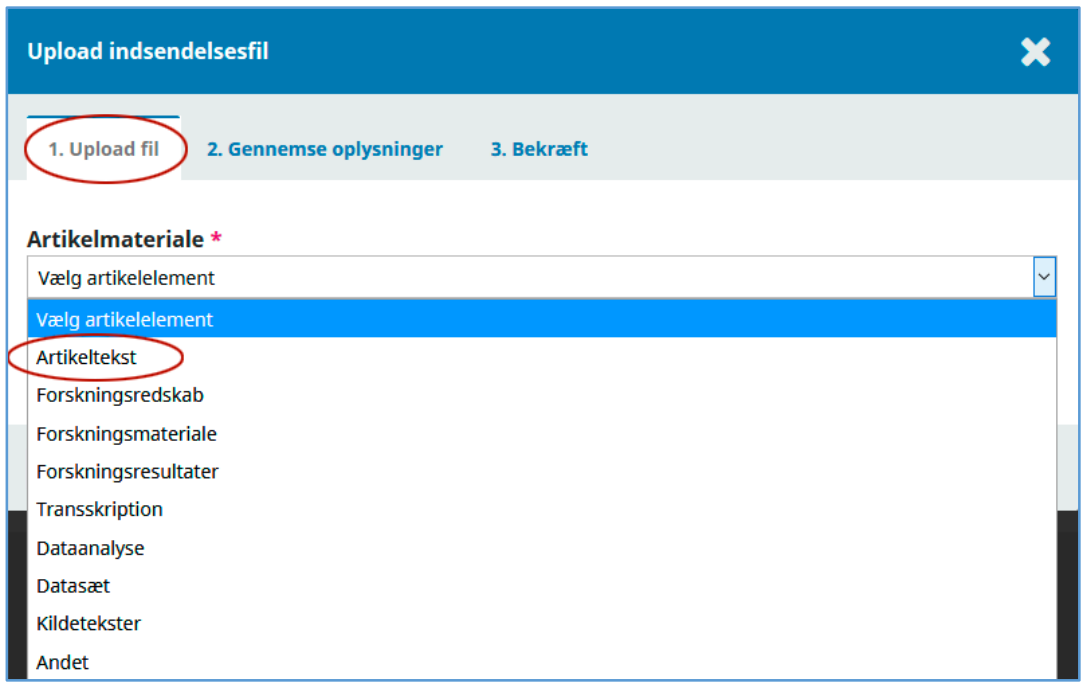

Klik på 'Upload fil', markér din html-fil og klik på 'Åbn'

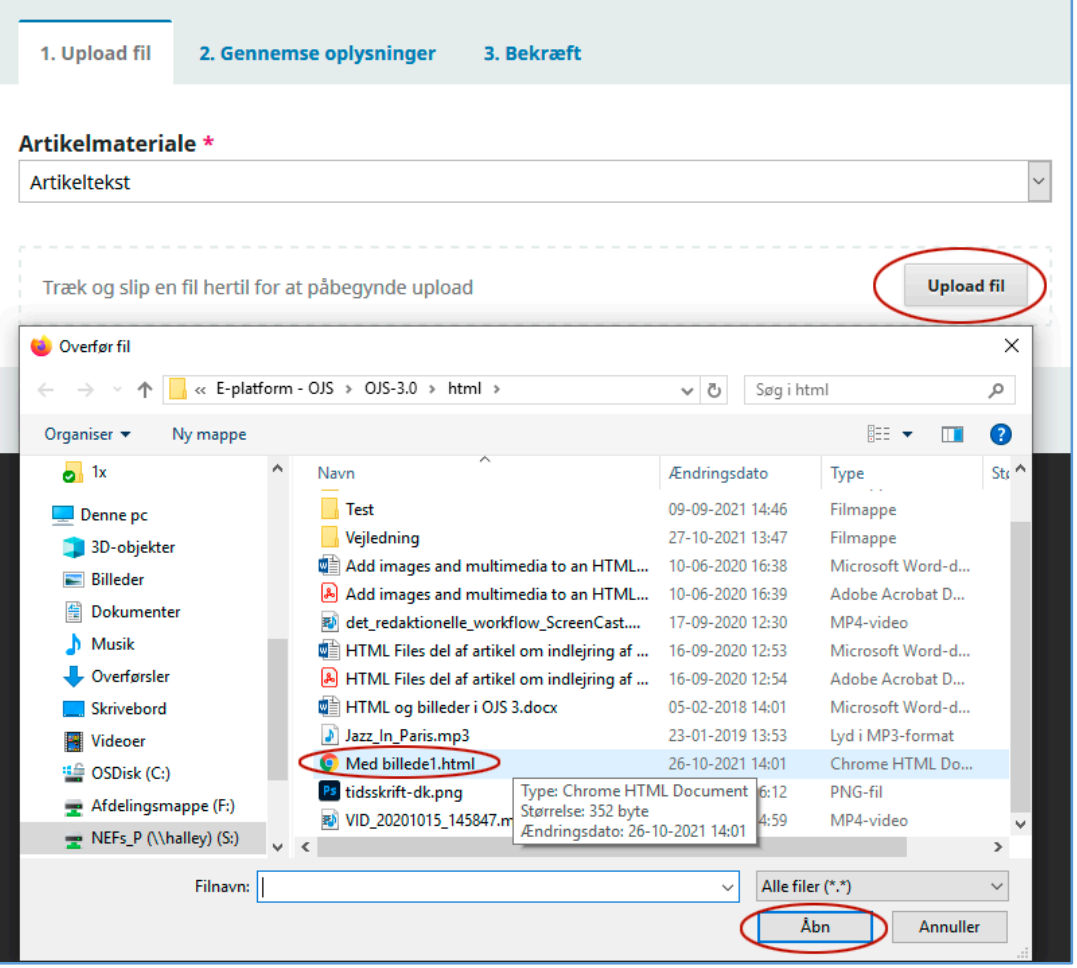




\section{Vælg så 'Fortsæt'}

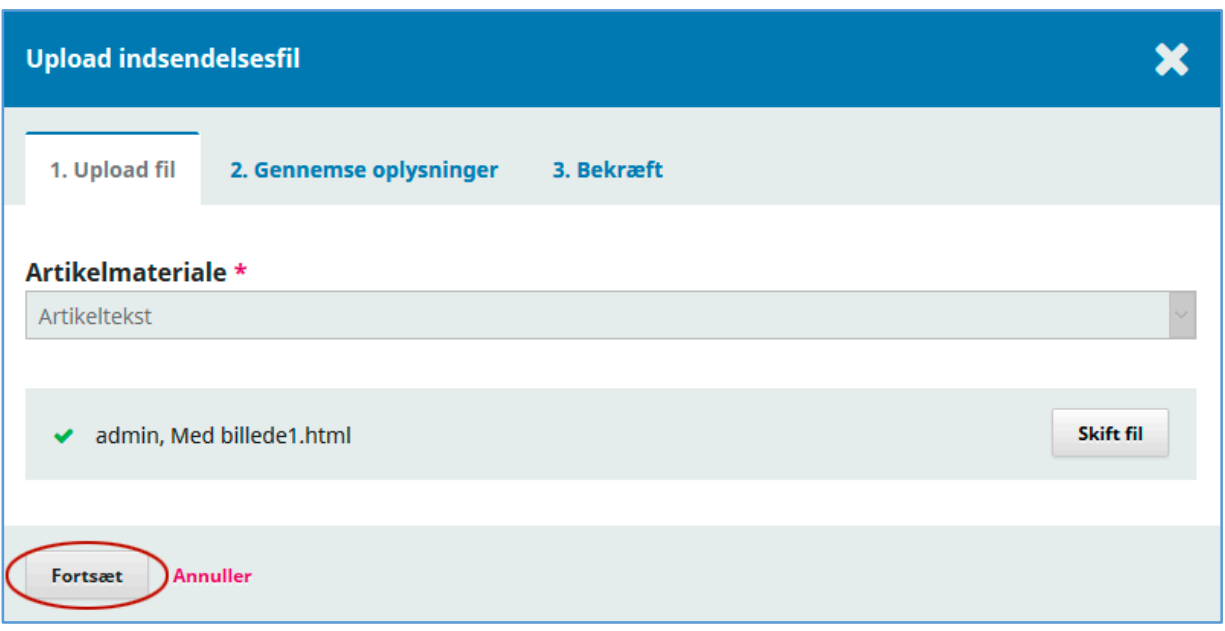

Herefter fremkommer der en side, hvor du kan uploade relaterede filer og det er her billedfilerne skal hentes ind. Klik på linket 'Upload fil'

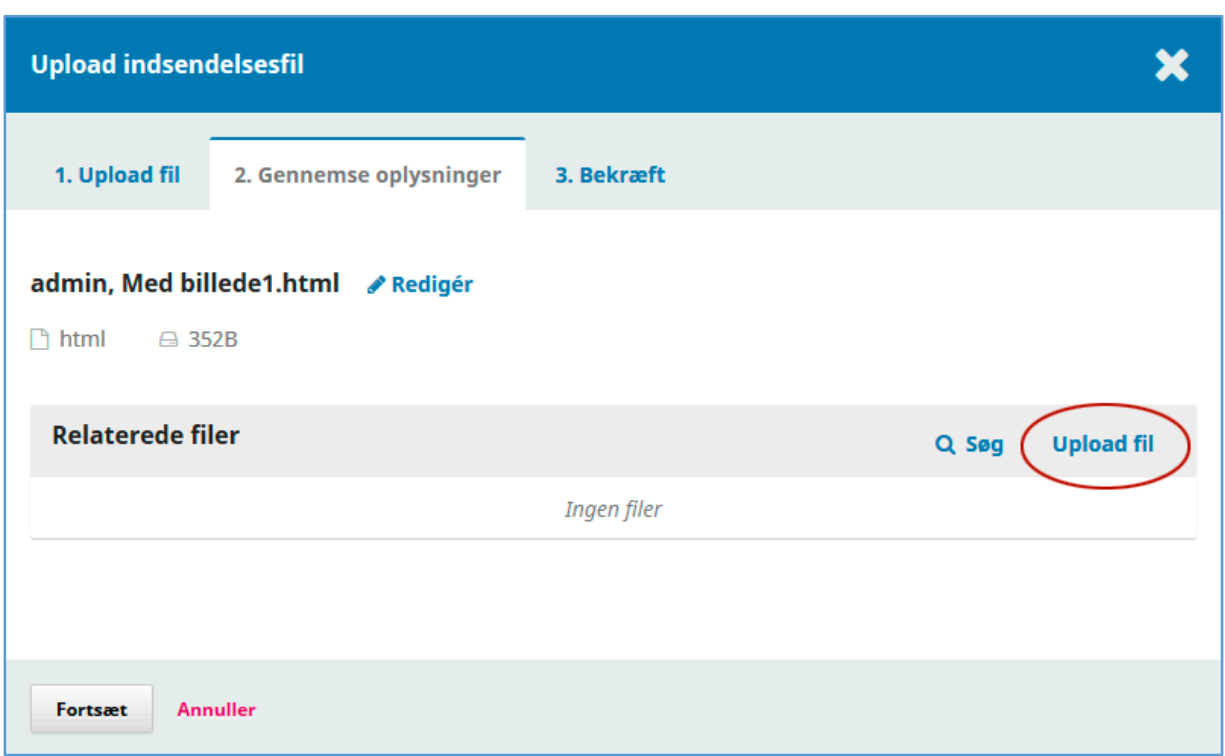

Nu åbner et nyt pop-up-vindue. Som artikelmateriale vælger du 'Billede'

\begin{tabular}{|c|c|c|}
\hline 1. Upload fil & 2. Gennemse oplysninger & 3. Bekræft \\
\hline \multicolumn{3}{|c|}{ Artikelmateriale * } \\
\hline Vælg artikelele & nt & \\
\hline \multicolumn{3}{|c|}{ Vælg artikelelement } \\
\hline \multicolumn{3}{|l|}{ Multimedie } \\
\hline \multicolumn{3}{|l|}{ Billede } \\
\hline \multicolumn{3}{|l|}{ HTML stylesheet } \\
\hline Fortsæt & iller & \\
\hline
\end{tabular}


Hvorefter du klikker på 'Upload fil'...

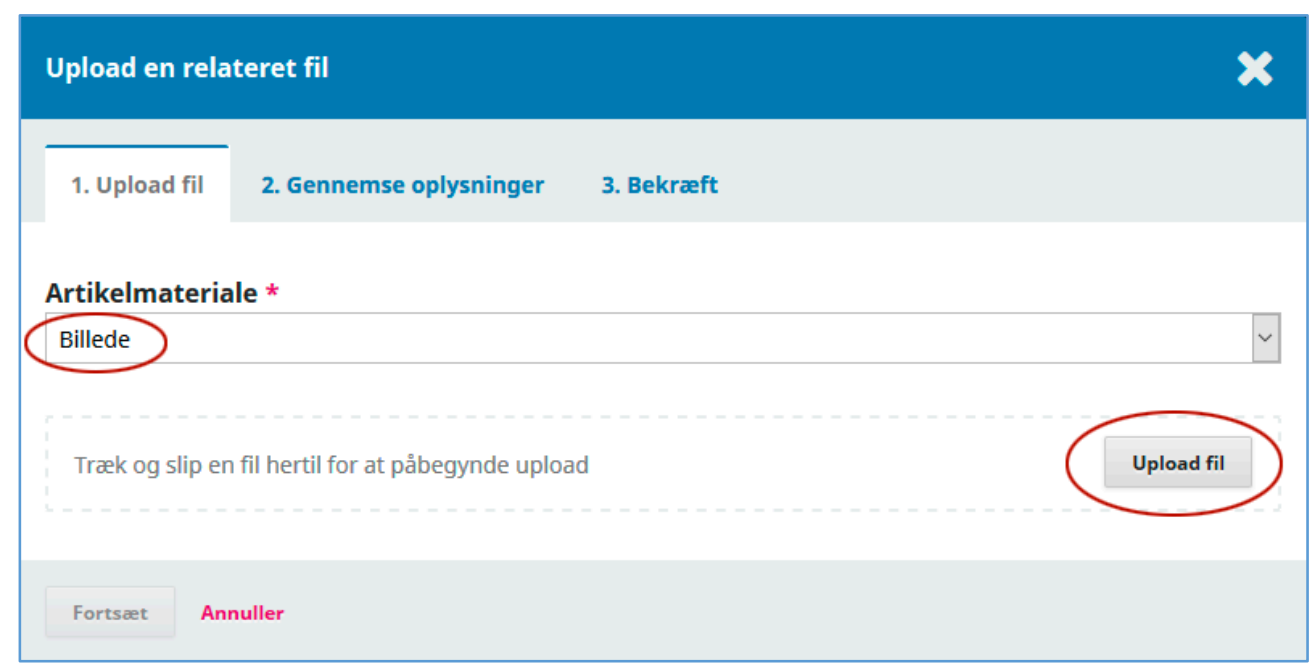

\section{.... og vælger det relevante billede}

Upload en relateret fil

\section{Artikelmateriale *}

Billede

Træk og slip en fil hertil for at påbegynde upload

Upload fil

(3) Overfør fil

$\uparrow$ « E-platform-OJS > OJS-3.0 > html ,

$\checkmark \circlearrowright$ Søgihtml

$\leftarrow \rightarrow \uparrow \square \ll$ E-platfo

Organiser $\quad$ Ny mappe

- $1 \mathrm{x}$

$\square$ Denne pc

3D-objekter

$\square$ Billeder

䑁 Dokumenter

d) Musik

$\checkmark$ Overførsler

- Skrivebord

国 Videoer

펼 OSDisk (C:)

Z Afdelingsmappe (F:)

INEFs_P (Ihalley) (S:)

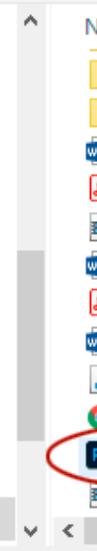

Navn

Test

Uejledning

W- Add images and multimedia to an HTML.

$\$$ Add images and multimedia to an HTML...

Fi det_redaktionelle_workflow_ScreenCast....

HTML Files del af artikel om indlejring af ...

$\$$ HTML Files del af artikel om indlejring af ...

WI HTML og billeder i OJS 3.docx

D) Jazz_In_Paris.mp3

Q Medbillede1.html

Ps tidsskrift-dk.png

(2) VID_20201015_1458

Filnavn:

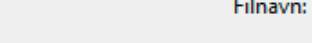

AEndringsdato: 12-04-2021 16:12

Andringsdato

09-09-2021 14:46

27-10-2021 14:00

10-06-2020 16:38

10-06-2020 16:39

17-09-2020 12:30

16-09-2020 12:53

16-09-2020 12:54

05-02-2018 14:01

23-01-2019 13:53

26-10-2021 14:01

12-04-2021 16:12

an 020 14:59

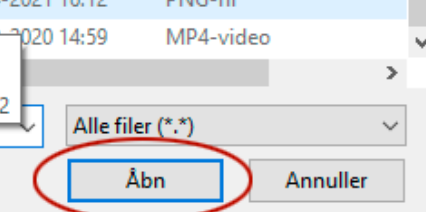


Så klikker du på 'Fortsæt'

Upload en relateret fil

$\begin{array}{lll}\text { 1. Upload fil } & \text { 2. Gennemse oplysninger } \quad \text { 3. Bekræft }\end{array}$

\section{Artikelmateriale *}

Billede

Under fanebladet '2. Gennemse oplysninger' fremgår det, at der foruden billedfilens oprindelige navn (tidsskrift.dk.png) er indsat et 'admin,' hvilket henviser til det brugernavn, jeg er registreret med i OJS. Dette skal fjernes så billedfilnavnet stemmer overens med det, der er anført i html-filen.

Derudover har du mulighed for at berige billedfilen med yderligere oplysninger såsom billedtekst.

$\square$ 704\&gange;103 pixels

\section{Billedtekst}

tidsskrift.dk

Copyrightindehaver

Fortsæet
Kildeangivelse

Godkendelsesbetingelser 
Når billedfil-navnet er i overensstemmelse med det, der er anført i html-filen går du videre i uploadprocessen. Klik 'Fortsæt'

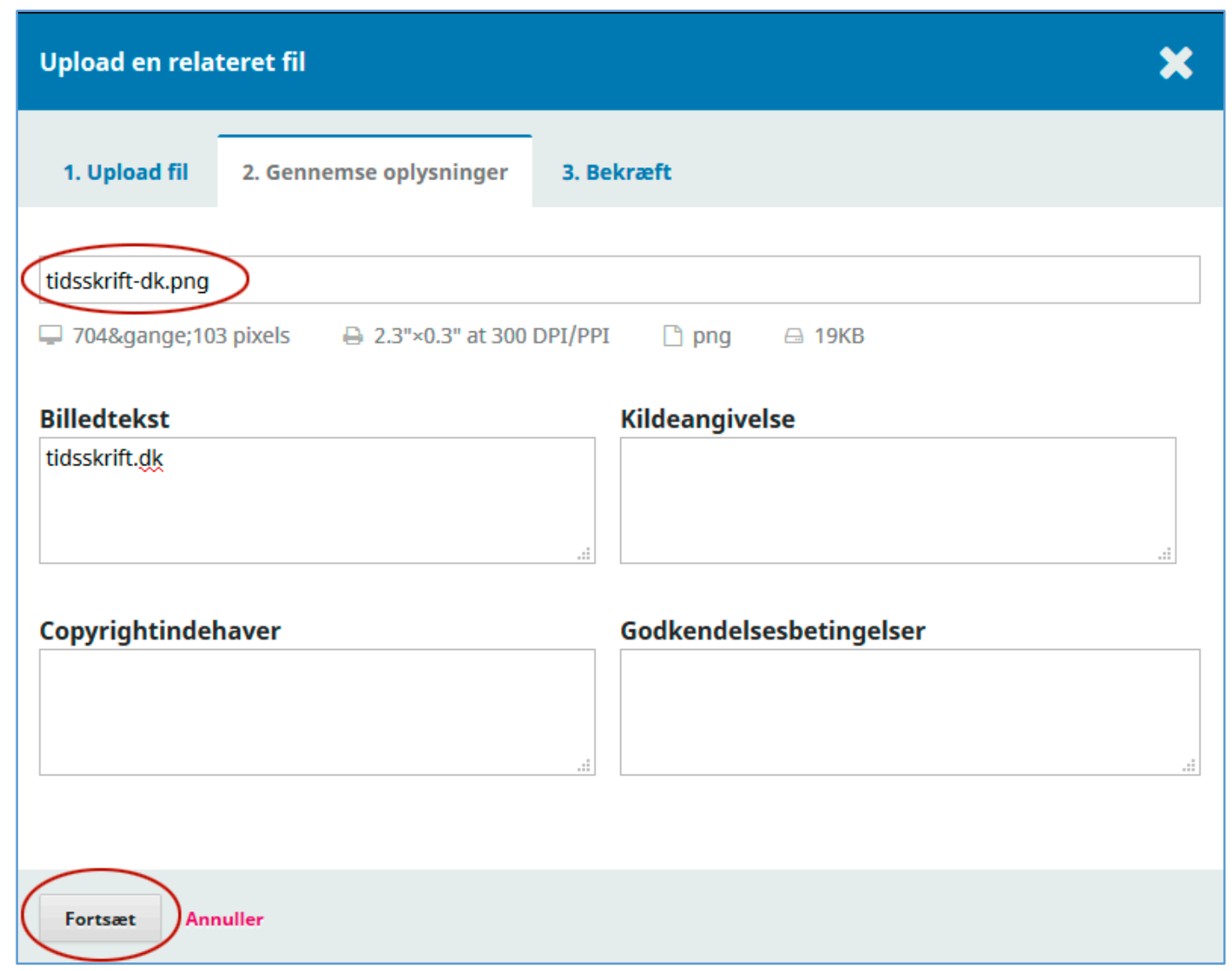

Hvis du skal have tilføjet flere billeder klikker du på 'Tilføj en anden fil' ellers vælger du 'Udfør

Upload en relateret fil

$\begin{array}{lll}\text { 1. Upload fil } & \text { 2. Gennemse oplysninger } & \text { 3. Bekræft }\end{array}$

\section{Fil tilføjet}

Tilføj en anden fil 
Nu er du tilbage i det oprindelige upload-vindue og her mangler du blot at få færdig-uploadet din html-fil. Klik 'Fortsæt'....

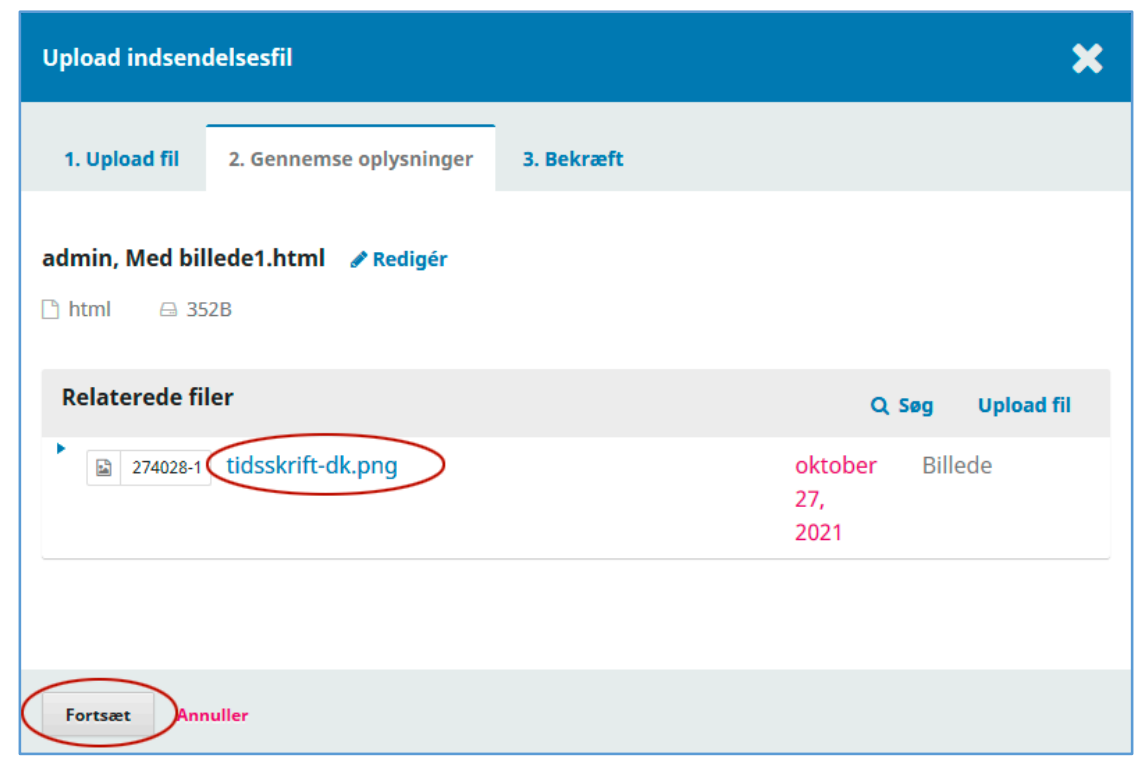

... og 'Udfør'

$\begin{array}{lll}\text { 1. Upload fil } & \text { 2. Gennemse oplysninger } & \text { 3. Bekræft }\end{array}$

\section{Fil tilføjet}

Tilføj en anden fil

Herefter går du videre til næste trin $\mathrm{i}$ indsendelsesprocessen ${ }^{1}$

\section{Indsend en artikel}

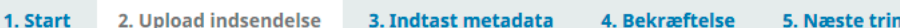

${ }^{1}$ Det samme er tilfældet, hvis du anvender QuickSubmit. Efter at have tilføjet publiceringsversionen går du også her videre på sædvanlig vis. 